\title{
Usability study on the interface of an artificial inteligence system for creativity support
}

\author{
Usabildade da interface de um sistema de \\ inteligência artificial para apoio à criatividade
}

Luiz Fernando de Carvalho Botega ${ }^{1}$

Jonny Carlos da Silva ${ }^{2}$

Gisele Raulik Murphy ${ }^{3}$ 


\section{Abstract}

Organizations should enhance its creativity skills, the basis to fulfill the changing customers' needs. Creativity techniques are powerful allies in the innovation process for building adequate ideas. Each technique has appropriate use situations, and selecting them requires experience from a facilitator. As a rare asset, human expertise can be represented using Artificial Intelligence approaches. The developed prototype identifies the design team's scenario through questions, correlating adequate creativity techniques. To develop a clearer and more intuitive system, we investigate interface and usability aspects through questionnaires with students and design specialists.

Key-words: Creativity; Usability; Knowledge-based systems; Artificial intelligence.

\section{Resumo}

Organizações devem aprimorar sua habilidade criativa para melhor atender às necessidades dos usuários. Técnicas de criatividade auxiliam no processo de inovação e no desenvolvimento de ideias adequadas. Cada técnica possui situações de uso apropriadas e a seleção delas requer experiência do facilitador. Como um recurso raro, expertise humana pode ser representada utilizando Inteligência Artificial. O protótipo desenvolvido identifica o cenário de projeto através de perguntas e correlaciona técnicas de criatividade adequadas. A fim de obter de um software capaz de mitigar possíveis erros de uso, investigou-se aspectos de usabilidade através de questionários com estudantes e especialistas.

Palavras-chave: Criatividade; Usabilidade; Sistemas baseados em conhecimento; Inteligência artificial.

ISSN: 2316-7963

1Doutorando em Engenharia Mecânica, UFSC (Ifbotega@gmail.com)

${ }^{2}$ Doutor, UFSC

${ }^{3} \mathrm{PhD}$, Universidade Positivo 


\section{Introduction}

Every system has a manner to interact with its user. Either computational or physical, this communication window is the main mode for information exchange, presenting a scenario to users, receiving data from them and responding if necessary. A deep understanding of the context and the target audience is required to analyze how different users interact with interfaces and how to make systems more usable and effortless (Sanders and Stappers, 2008). Usability studies reveal ways to improve computational prototypes, adapt systems to the user's language and ease their understanding (van Kuijk et al., 2015).

To refine a system's design and development, a usability test was performed to validate interface and applicability of a Knowledge-Based System (KBS) for supporting creativity in design. A KBS is an Artificial Intelligence (AI) approach able to emulate human decision-making ability, providing empirical knowledge in a more available, reliable and permanent framework (Giarratano and Riley, 2005). After identifying designer's needs, the KBS can select creativity techniques, providing explanations on the computational reasoning process, and information on how and when to use each technique. By translating knowledge from an expert to a computational environment, the KBS prototype builds a bridge between creativity techniques and design process (Botega and Silva, 2015).

This approach allows a broad system, aiming for various design teams in need for creativity support. An initial set of questions identifies the scenario and correlates them to techniques, which are readily presented and explained for use. To answer the questions and afterwards execute the techniques, the user should first understand the interface and language of the system prototype. Usability plays a key-role in the human-computer interaction and its understanding offers valuable information on how to create a useful helper for design (Patel and Kannampallil, 2015).

This paper aims to report the validation process of the system, focusing on study four usability aspects:

- Language of input questions;

- Interfaces of questions and creativity techniques output;

- Adequacy and language of outputs;

- Overall performance of the system.

The usability study process was performed through questionnaires, with nine validators running individually the software and reporting their impressions. This work follows with a brief literature review on creativity and innovation (section 2), design methodology (section 3), and knowledge-based systems (section 4); the initial prototype, the development of the usability study and achieved results (section 5), and conclusions and future works (section 6).

\section{Creativity and innovation}

Creativity is a basic human instinct (Amabile, 1997; Bertoncelli et al., 2016). Since the beginning of our evolution, humankind developed a need to come up with alter- 
natives in order to prevail and survive. Initial tools of stone gave place to stronger materials as metals and ceramics. This creational and innovational instinct developed over the years to a much more refined, structured and conscious concept (Forty and Soares, 2007). Currently, creativity can be defined as the process of reaching great quantity and diversity of new and adequate ideas, and converge them into solutions that befit the original need (Belski et al., 2016). Innovation works as a verification, implementing creativity into a feasible, viable and usable reality (Amabile, 1997; Gabriel et al., 2016). Sole creativity is unreal and impracticable, while sole innovation gives predictable and unoriginal solutions.

The creation process is commonly structured in stages. It starts with an initial Inspiration; followed by a rational stage of Preparation; an unconscious phase of ideas Incubation; the discovery of an concept in Illumination; and finally the Verification of such idea's usefulness to the problem at hand (Mostert, 2007; Baxter, 2011). This progression, although commonly not so linear, allows the visualization of the process' bottleneck: the incubation phase (Mostert, 2007).

Time resource is scarce in current competitive world and should be shortened to maintain productivity (Žnidaršič and Jereb, 2011). Without adequate tactics to abbreviate this stage, a capable team may reach a creativity block, requiring valuable time to develop the ideas into solutions. In order to reduce time requirements in creation, the use of creativity techniques arises as a process catalyzer, giving the design team different routes to find possible solutions (Bertoncelli et al., 2016).

Unfortunately, many design teams still have difficulty in identifying and using appropriate techniques (Santanen et al., 1999; Chen et al., 2015). A vast literature with over 600 techniques is available (Nijssen and Lieshout, 1995), but some are hard to reach due to field-restricted language, lack of technical dissemination, or even study field bias. Creativity can be seen as an interdisciplinary concept, but each area has particular focus, which hamper knowledge dissemination.

\subsection{Impact factors on creativity and innovation}

According to Amabile (1997), creativity in the individual sphere is a result of combinations between expertise, creative skills, and intrinsic task motivation. While expertise and intrinsic motivation depend on the team background and personal factors, creative skill is a trainable aspect (Starkey et al., 2016). Adequate approaches, such as creativity techniques, can provide higher cognition flexibility, pushing team members to be more tolerant to risks and creating adequate ambiance to develop the creative thinking (Bertoncelli et al., 2016).

To appropriately explore those individual skills, an organizational environment should be adequate in also three components, according to Amabile (1997): organization motivation to innovate, resources, and management practices. Training and knowledge are imperative resources for innovation to occur, which includes information on how to select and use creativity techniques to provide a sufficient base to creation.

The individual and organizational factors interact in a mutually supporting way, 
as presented in Figure 1. New ideas and lateral thinking are the basis for new products, feeding the process with alternatives and possible needs to be addressed. By its turn, the work environment and organizational posture have a deep impact on creativity effectiveness (Bourgeois-Bougrine et al., 2017). Open, cooperative, focused, and experiment-oriented environments benefit creativity (Amabile et al., 2002; Back et al., 2008; Brown, 2010), especially for task motivation purposes.

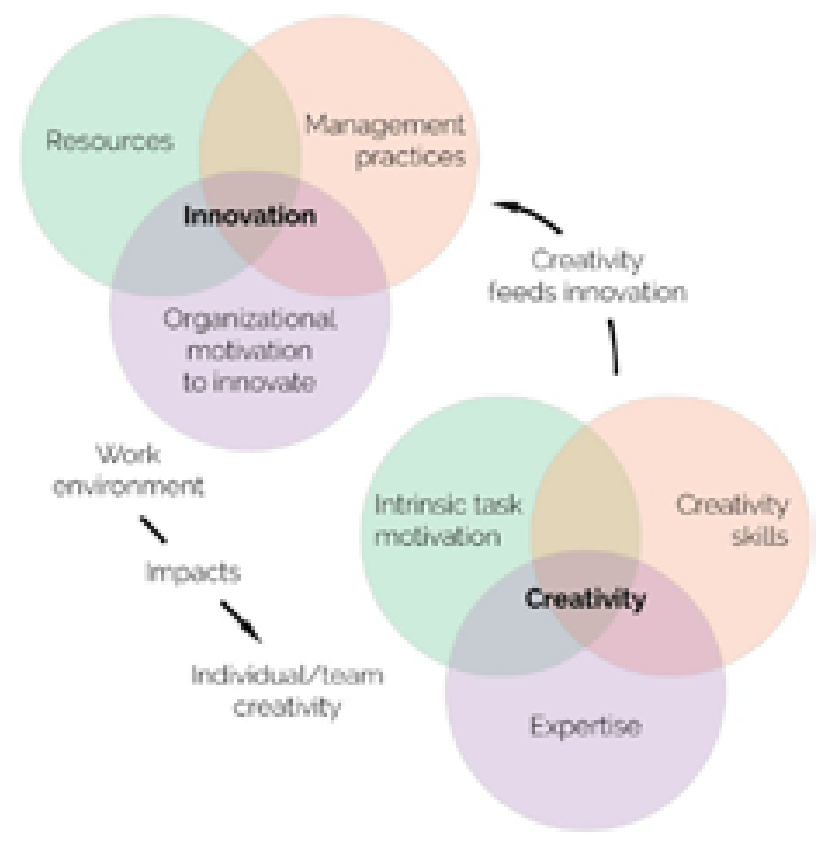

Figure 1: Componential Theory (Adapted from: (Amabile, 1997)

The developed KBS prototype does not intend to be creative or inventive by itself, but to serve as an alternative to enhance the creative process. Many factors during a design development are required, but adequate resources, environment, motivation and personnel can boost creation and innovation. Other barriers during the product development may also interfere in the process such as incorrect definition of the task, functional fixedness, excessive specialization, rejection of ideas from non-specialists, fear of criticism and early judgment (Back et al., 2008). An organization can prevent such problems with a systematization of the design process, possible with the usage of adequate methodologies to frame the work and keep the team aligned with the guidelines of the design and the organization (Baxter, 2011).

\section{Design methodology}

The increasingly complex needs from users and stakeholders press teams to deal with conflicting requirements, imposing on them constant trade-offs to better meet the design specifications (Kwong et al., 2016). While consumers seek innovative, easy, and good quality products, companies need revenue to maintain itself, and some stakeholders are still focused on profit (Baxter, 2011). This decision-making process can benefit from structured research based on previous developments and studies to evaluate adequate methods to design (Back et al., 2008; Baxter, 2011). 
A greater focus on market, in opposition to technocentry, increases the chances of success of a product up to five times (Brown, 2010; Baxter, 2011). Human-centered methodologies base itself on empathy with users, co-creation, multidisciplinary teams, prototyping, and a set of techniques to help the team achieve a real understanding of users during development (Vianna et al., 2012; IDEO, 2015). Their documented experience (IDEO, 2011; IDEO, 2015) as well as developed methods (Brown, 2010) and techniques indicate approaches to improve creativity and innovation, but lack the structure to select specific techniques during development.

\subsection{Engineering methodology}

While the beforementioned approaches serve as heuristics for design, the required structure can be attained by incorporating a prescriptive engineering methodology, such as the Integrated Product Development Process (PRODIP) (Back et al., 2008). This methodology converges methods from engineering, production, manufacturing, design and other areas to serve as guide for design, creating a structure of stages and tasks that should be done for the development of a product. In this methodology, product development is divided into three main phases (Back et al., 2008):

- Design planning: sets the basis for the project to be executed, delineating the project scope, specifying needs to be addressed, target users, goals, team composition, and management guidelines;

- Design process: is the core of the project, going through knowledge acquisition about the domain, ideating conceptions, converging to solutions, prototyping, solution definition, technical drawings and manufacturing plans development;

- Implementation: encompasses the post-development of production, pilot manufacturing, market validation and launching of the product.

\subsection{Creativity aspects on methodology}

Creativity is an important skill for the development of new products and is intensively used on the first two phases of the PRODIP methodology. Design planning requires divergence of ideas to choose a problem that is real and relevant, and convergence to defined criteria and choose which guidelines the design will follow. Design process focuses on diverging conceptions and converging them into feasible solutions. Double Diamond methodology can be seen as an approach that specifies the development in terms of creativity and innovation (Design Council, 2015), as shown in Figure 2.

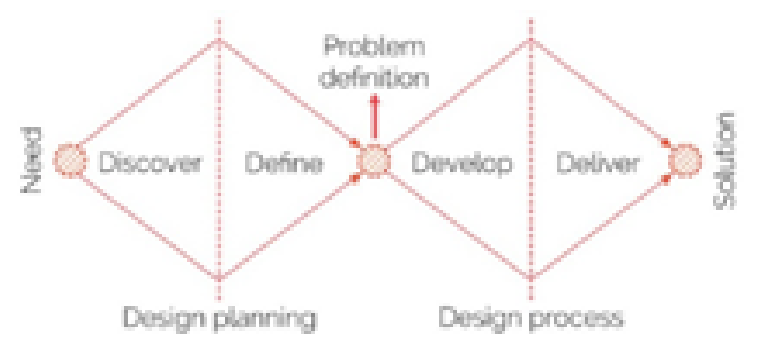

Figure 2: Double Diamond methodology (Adapted from: (Design Council, 2015) 
The four-phased methodology stands closer to human-centered design approaches, while still providing enough basis for the categorization and selection of techniques. Naturally, it is difficult to delineate these phases during real development, and many variables influence on the right creativity techniques selection. The sorting should take into account each team's behavior, expertise, and specific needs of the situation.

To ease information access for design teams, considering the large amount of techniques reported in literature, the development of a computational method such as a KBS is valuable. This approach allows the gathering of theoretical findings and scattered information about techniques into a centered guide to assert adequate creativity techniques. For this prototype, the second diamond was prioritized, for being considered the main step for product conception. The prototype system serves as a bridge between the expertise for creativity techniques selection and the design team.

\section{Knowledge-based systems}

Artificial intelligence (Al) can be defined as "the study of how to make computer do things that, at the moment, people do better" (Rich et al., 2009, p.3). Al implementations serve as a supporting approach for time reduction, permanence enhancement, raise in reliability and in availability (Silva, 1999), being used even to support teams or specialists on making decisions, or offering second opinions (Giarratano and Riley, 2005).

Study fields branched out of the concept of Al, including the Knowledge-Based Systems (KBS). The KBS approach captures the knowledge of an expert (or a team of experts) to emulate their decision-making ability (Ikram and Qamar, 2015). It uses inferences to correlate user's needs to the knowledge base available in the system (Giarratano and Riley, 2005). Figure 3 shows a simplified scheme of the development and key-players of a KBS. A knowledge engineer (KE) acquires information from human experts (HE), usually through interviews and questionnaires, which serves as basis to structure the necessary knowledge to create the KBS. The program is then implemented, acting as a bridge for the knowledge to pass from expert to user, especially when direct contact is difficult (Ikram and Qamar, 2015).

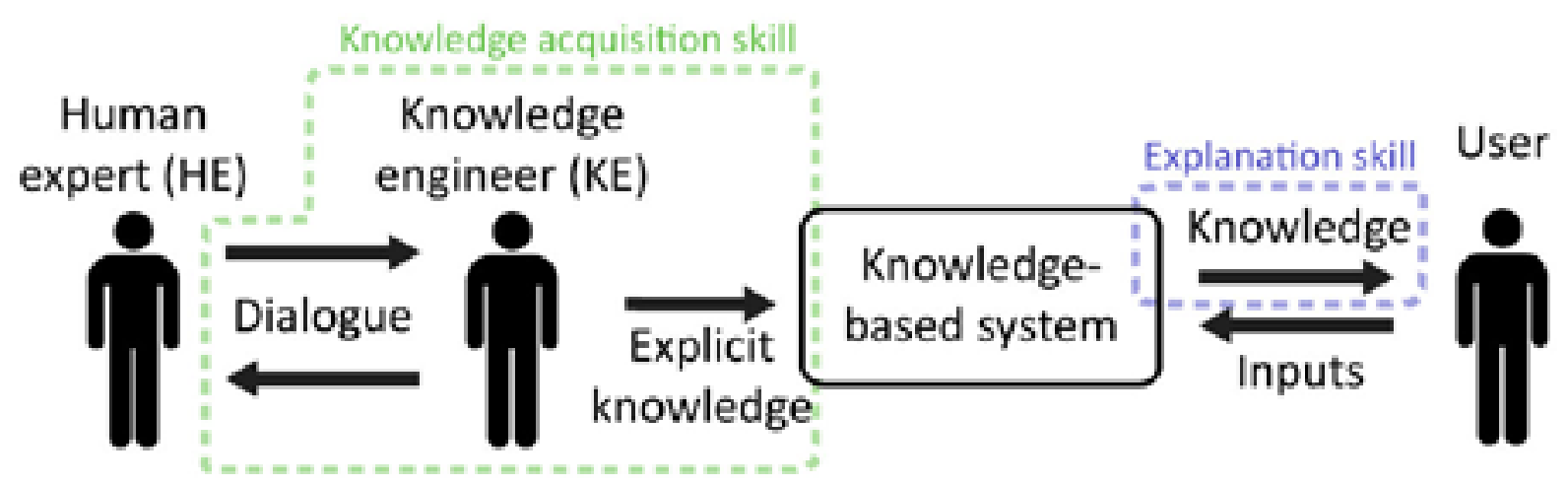

Figure 3: KBS development and key-players 
The implementation should still undergo verification and validation phases, ensuring its accuracy and effectiveness (Silva et al., 2014). Verification focuses on analyzing the technical system for incoherence and bugs. Validation tends to be more costly and difficult, checking the system coherence to reality. This task is usually carried out with experts other than the main $\mathrm{HE}$, who can give a deep evaluation of the content, and non-experts, who test interface, easiness of use and effectiveness of outcomes.

\section{Prototype and usability}

To represent the desired information, the KE should interpret the data received from the HE and translate it to an easy-to-use system, adapted to the targeting customers. A KBS requires logical structures to generate adequate outcomes. Although creative thinking is essentially complex and inherent of the human being, the assertion of adequate creativity techniques can be structured, taking into account the heuristic knowledge of facilitators. The techniques classification into the following five categories, each with attributes and values, is the basis of this development (Botega and Silva, 2015):

- Design step: develop / deliver;

- Innovation focus: incremental / architectural / radical;

- Team relationship: interactive / dissociated;

- Execution method: verbal / symbolic;

- Difficulty of use: low / moderate / high.

The software used to develop the prototype (CLIPS v6.30) is based on the command prompt interface presented in Figure 4, with direct questions answered by the user. The system prototype features nine questions (presented on Table 1). Combinations of answers can identify up to 504 entry scenarios, all of which have at least one technique selected, from a set of 24 output creativity techniques available. An entered scenario is processed by the prototype using a double inference process from questionnaire to the abovementioned categories, then from categories to techniques.

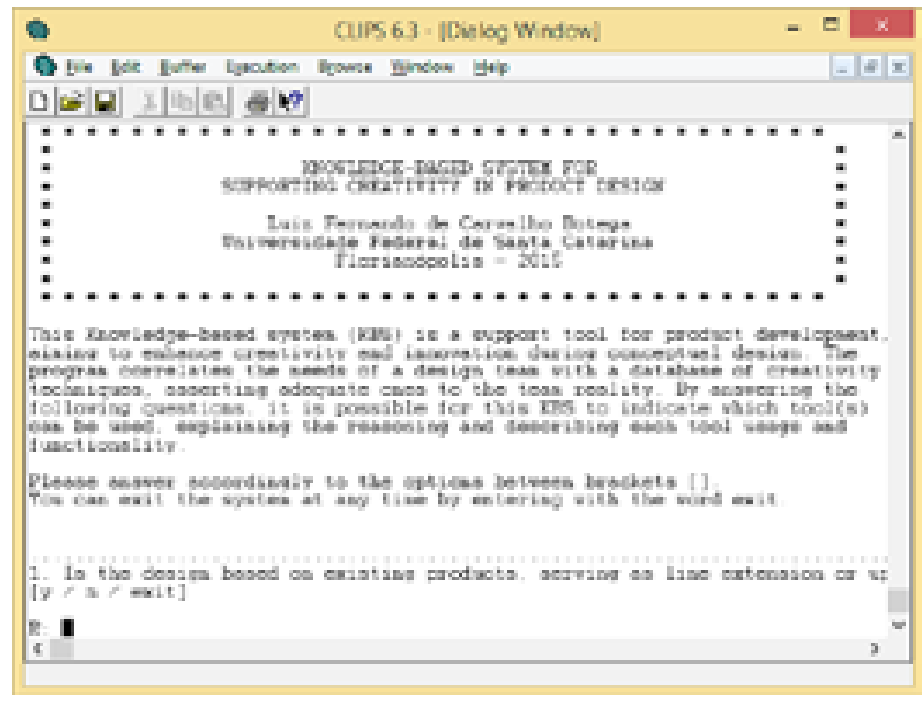

Figure 4: KBS prototype interface in CLIPS v6.30 


\begin{tabular}{cl}
\hline 1 & $\begin{array}{l}\text { Is the design based on existing products, serving as a line extension or } \\
\text { upgrading of parts? }\end{array}$ \\
\hline 2 & $\begin{array}{l}\text { Does the design aim to fulfill different needs in relation to the original } \\
\text { product, targeting new functionalities or new markets? }\end{array}$ \\
\hline 3 & $\begin{array}{l}\text { Are the number of generated ideas and concept alternatives sufficient for } \\
\text { the team? }\end{array}$ \\
\hline 4 & Is there time available for posterior tasks according to the timeframe? \\
5 & $\begin{array}{l}\text { Is the team multidisciplinary, i.e. having members with different expertise } \\
\text { in direct and continuous contact? }\end{array}$ \\
\hline 6 & $\begin{array}{l}\text { Does the team have an exclusive physical environment (e.g. dedicated } \\
\text { room)? }\end{array}$ \\
\hline 7 & $\begin{array}{l}\text { Does the team have online communication for design purposes, sharing } \\
\text { progress and information? }\end{array}$ \\
\hline 8 & $\begin{array}{l}\text { Does the team have periodical meetings (daily or weekly) among all } \\
\text { members? }\end{array}$ \\
\hline 9 & $\begin{array}{l}\text { Does the team have a good relationship among each other to exchange } \\
\text { information and for mutulal assistance? }\end{array}$ \\
\hline
\end{tabular}

Table 1: Initial set of questions for the KBS

The target public for this KBS encompasses any design team in need for creativity techniques, composed of product or industrial designers, engineers, and multidisciplinary groups with basic knowledge of product development. The initial set of questions was developed to identify characteristics about development purposes, team configuration, and organization orientation. The outcome of the system is a set of techniques considered adequate to the current scenario of the design team, as well as a series of explanations of the chaining that let to each technique (fundamental aspect of any KBS) (Silva et al., 2014). They are presented in form of a HTML file, as shown in Figure 5, which contains easy access data to appropriately use each technique.

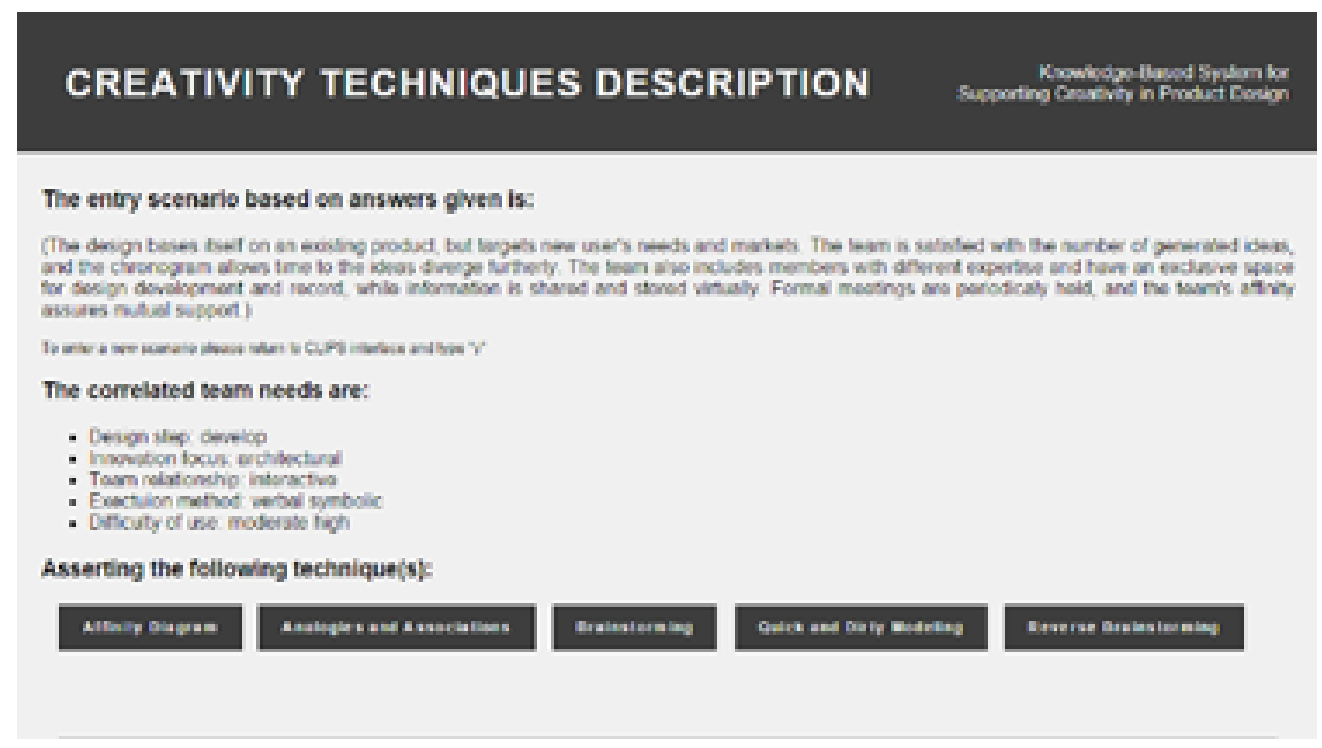

Figure 5: Initial output interface

As part of the validation process of the developed KBS, a usability study was structured to identify potential areas of improvement for the system. Experts and non-experts in design and engineering were surveyed, giving their opinions and impressions 
on the relevant aspects of the system. From the nine validators involved, three were creativity experts, although all validators have practical and/or theoretical knowledge in the design process and its structure. Interview questionnaires were virtually sent, answered and received in a period of three weeks, depending on the validator's availability. Answers from experts are anticipated to be more detailed and insightful, while non-expert relevance relies on overall system usability such as interface and used language.

\subsection{Usability study}

To verify and validate if the system is understandable and useful for any design team, a usability study with engineers and designers was formulated. Being a computational system, the interface should be suitable to the target public, making the navigation intuitive and preventing mistakes or doubts. The importance of friendly environment goes beyond appearances. Understanding how users interact with the software and how the interface will be used reveal important information on how to make the system more useful with less effort. An interface that mitigates errors is fundamental to allow a good performance of the system and avoid mistakes (Misnevs and Demiray, 2017). The KBS is only usable if the user can correlate their design situation to the questions, and understand the presented outcomes and explanations.

"Human errors" is a common label for users not familiar with an interface, and is usually seen as lack of practice or ignorance about the content. Many errors that are assigned to lack of knowledge from users have their real roots on a "design error", or a lack of usability (Stanton and Baber, 2002). The prediction of those flaws is fundamental while developing a successful product or service and directing it to users. To effectively address errors and improve solutions, a live testing prototype and usability studies are essential.

Ways of performing usability studies vary from questionnaires and interviews to prototype direct use, all according to the needed deepening on current design stage. The aim is to understand how and why users interact with the system and which features can be improved. It is important to notice that what users say is not necessarily what they experience, since many factors can distort their answers. The required timeframe for this work and agenda of the validators hampered those approaches, limiting to questionnaire applications.

First information required for such evaluations include by whom, why, when, and where the system will be used. As previously mentioned, this prototype is directed to any design groups in need for creativity boosts during development, on stages that range from conceptual discovery to solution identification. The system can be used anywhere with the aid of a computer, being flexible and available at any time.

This study is limited to ease the understanding and apply the feedback in optimizing the KBS. The developed questionnaire embraces four aspects of the validation process:

- Language of input questions;

- Interfaces of questions and creativity techniques output; 
- Adequacy and language of outputs;

- Overall performance of the system.

On the validation questionnaire, a brief introduction justifies and explains the study context for the validator. The questionnaires were answered individually after operating the prototype several times, and three different hypothetical scenarios were developed to help adding background to the simulation. It is important to notice that every input combination was considered adequate, and the questionnaire aims to evaluate the KBS, not the validators understanding of those scenarios. To run the KBS prototype, a simple 'Read-me' file provides instructions on how to run the program, from extracting files until the procedure for feedback. Nine questionnaires were answered up to date and they provide sufficient base for the prototype current version.

\subsection{Results}

As expected, expert validators directed their answers to the relevance of the theme and coherence of the outputs as well as overall usability, while non-expert focused on system use and interface. First aspect to be noted addresses improvements in the system's questions language, item mentioned by 3 of the validators as shown in Figure 6. The used technical repertoire limited the comprehension and hampered users from different background to overlap the real scenario to the questions. By using a more accessible language, the system can be directed to a wider variety of users including non-experts in design methodology. The new system questionnaire is presented below on Table 2.

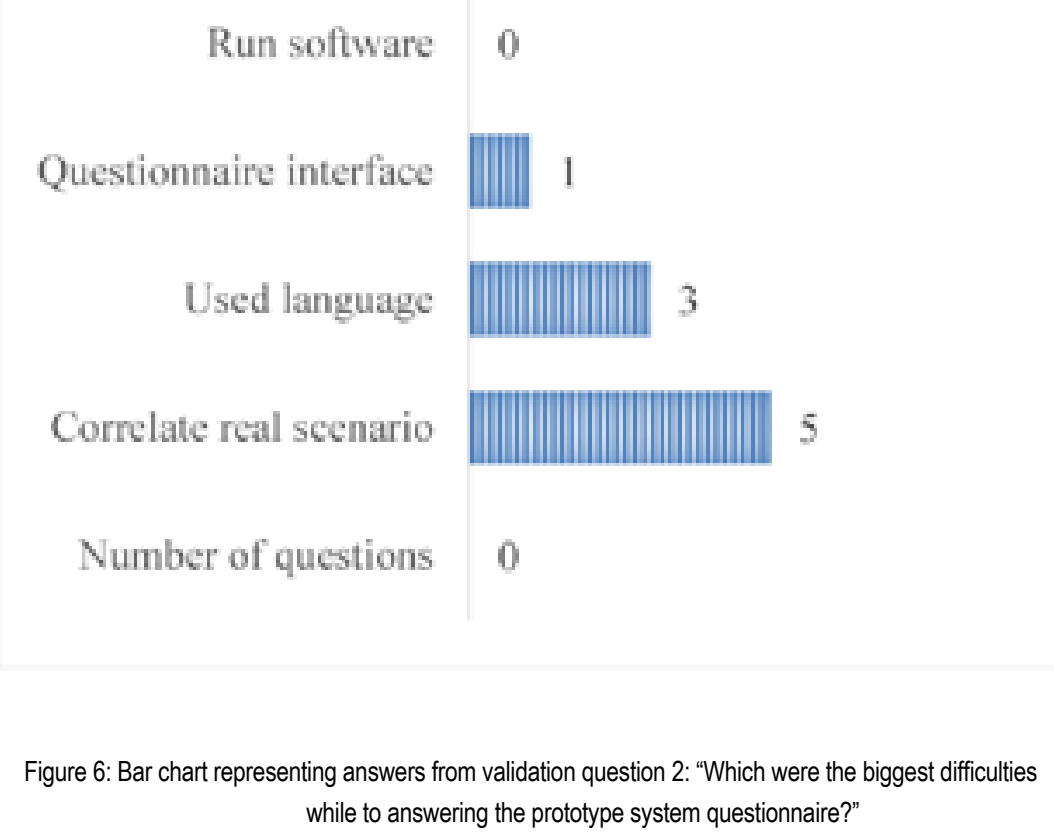




\begin{tabular}{cl}
\hline 1 & $\begin{array}{l}\text { Is the project based on existing products, focusing on keeping them in } \\
\text { the market? }\end{array}$ \\
\hline 1.1 & $\begin{array}{l}\text { Does the project focus on coming up with new functions or reaching } \\
\text { different users with the current product? }\end{array}$ \\
\hline 2 & $\begin{array}{l}\text { Are the number of generated ideas and alternativos satisfactory for the } \\
\text { team? }\end{array}$ \\
\hline 3 & $\begin{array}{l}\text { Is there time available to explore ideas and alternatives? } \\
4\end{array}$ \\
$\begin{array}{l}\text { Does the team have members with different backgrounds and expertise } \\
\text { (multidisciplinary) in close and constant interaction? }\end{array}$ \\
\hline 5 & $\begin{array}{l}\text { Is there a dedicated room or an exclusive physical environment for the } \\
\text { team? }\end{array}$ \\
\hline 6 & $\begin{array}{l}\text { Does the team have online communication to help sharing progress and } \\
\text { information about the design? }\end{array}$ \\
\hline 7 & $\begin{array}{l}\text { Does the team have periodical meetings (daily or weekly) with all } \\
\text { members? }\end{array}$ \\
\hline 8 & $\begin{array}{l}\text { Does everyone on the team nave good relationship to help each other } \\
\text { and exchange information? }\end{array}$ \\
\hline
\end{tabular}

Table 2: Restructured (new) initial set of questions for the KBS

Other aspect addressed by the language is the easiness to correlate real scenarios and questionnaire, as 5 validators replied to have difficulties in this correspondence. By using less technical questions, the system becomes more understandable and easier to correlate. To evaluate better options of information input, the prototype should be submitted to real design situations, on which the information required to answer the initial questions is more evident. By using hypothetical scenarios, the validation questionnaire may not entirely address this aspect. No validator mentioned complications with the number of questions or the execution of the software.

The initial set of questions interface presented low difficulty (1 validator), especially for being an unfriendly environment. Given the validators' technological background, the difficulties derived from interface may be greatly magnified in other use scenarios, which may include designers with little to no contact with command prompts. To ease and quicken the use, a front-end interface was developed using NetBeans IDE 8.2 (Java language) for implementation. The new system's questionnaire interface included an overall presentation of the system (Figure 7), and the nine questions divided into three screens (represented here in Figure 8 for the first three questions). The execution of the KBS code (performed automatically in background after clicking on "Let's create!") is only allowed after answering sufficient questions.

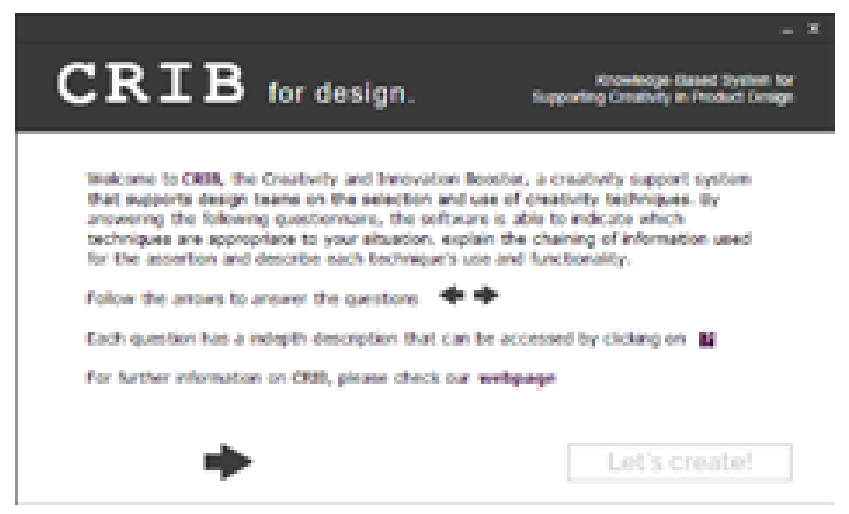

Figure 7: KBS first interface with the system's overall information 

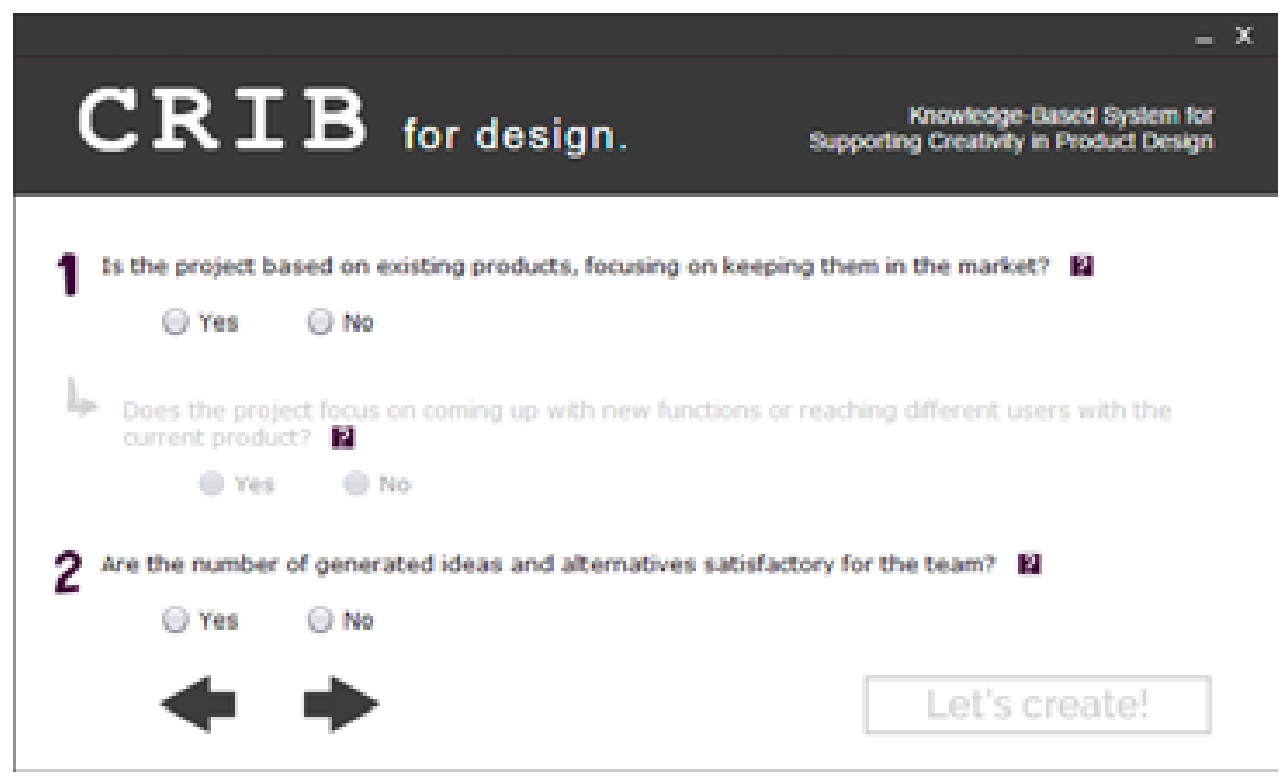

Figure 8: KBS interface with initial questions for users

The new interface may aid the execution of the system and ease answering the questions for a wider spectrum of users, especially due to the "help" icon with detailed information presented at the right side of each question. The visual impact and style identity of the system may also benefit the software, promoting a better cohesion between entrance and exit interfaces.

All validators considered the output techniques adequate to the presented scenario, but mentioned that other techniques may also be useful. The system presents what is considered the adequate ones inside the spectrum of available techniques, but does not limit the use of other techniques if the team decides. The KBS is a consultation and advice assistant, but the decision to use a technique is delegated to the team's choice. No validators said to have difficulty employing them, but mentioned that less experienced users might find it challenging to effectively use the techniques due to extensive use of text on the output.

The KBS prototype initial output method aimed to simultaneously describe the technique and help user effectively employ them. It counted with a set of information, explaining the correlation that led to the technique, presenting a resumed overview, situations in which each technique is adequate, a step-by-step, some tips for use, examples, related techniques and complementary readings. Validators reported a bigger focus on "what" is the technique rather on "how" to use them. This unbalance made the system more information oriented, lacking effective and direct usability. By relying on descriptions and tips, the system was directed to facilitators and users with experience on creativity and its dynamics, limiting comprehension of users with lesser knowledge on this area.

Based on answers to the validation question 7, as shown in Figure 9, adjustments on the implementation focusing on examples and more direct information help to broad the KBS to less experienced users and align it to its original intention. A total of 6 validators mentioned a need for more visual and first-hand information as in more examples, mentioning specially videos of techniques application (5 validators). 
A division between "how to use" and "what is" the technique may enhance usability, presenting the first directly and leaving the second as additional information. Users can easily and readily navigate through examples and learn to use the technique, but still access more detailed information, descriptions and references.

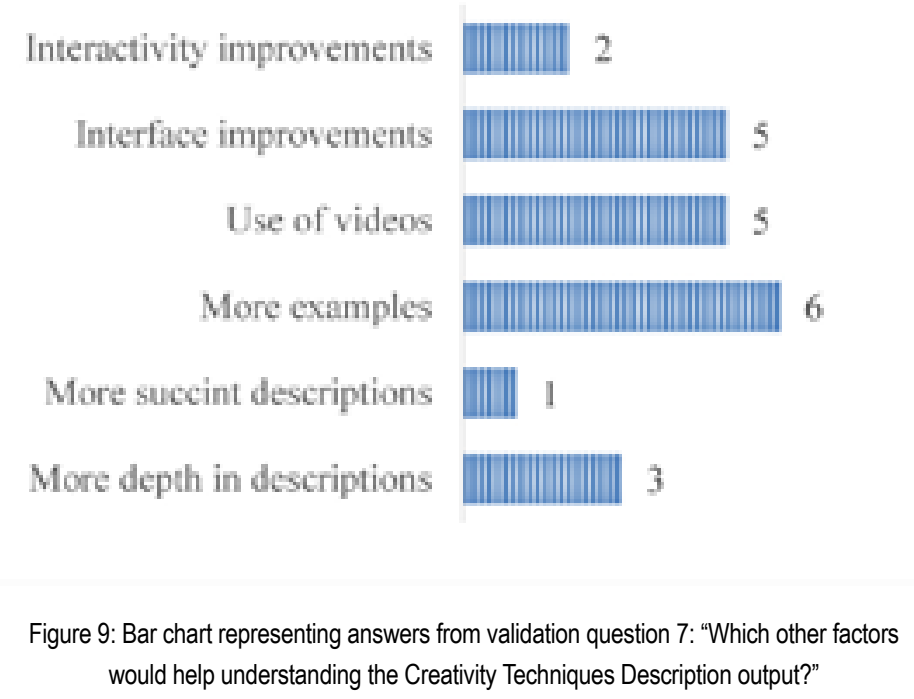

Interface alterations (indicated by 5 validators) and interactivity improvements (indicated by 2 validators) intend to ease consultation and give more fluidity of use. The wanted information should be readily displayed, and the intensive use of texts hampers the required quickness. By using schemes, infographics, videos and visual examples, the KBS would tend to be more accessible and valuable to real life usage.

To address the interface usability issue and focus the system on a less informative and more practical environment, the output HTML was subdivided into two different interfaces. After answering the initial set of questions, the user is presented with a report (Figure 10) that schematically indicates the inferencing process used to define the scenario. On the same interface (Figure 11), the user can navigate through the correlated techniques, comparing them in order to choose one that better fits their needs. For that, a set of highlights were added to each technique, providing more insight information for the team.

After comparing and choosing a creativity technique, the team is redirected to a webpage (Figure 12) that contains further information on "how to use" and "what is" the selected technique. The first comprehends step-by-step of use, examples and tips, while the second compiles information for the user to deepen the knowledge if needed. This second interface contains also information on other techniques, which the user can access freely.

From the 24 current techniques set, no single validator mentioned knowing more than 17, keeping an average of 12 known techniques. This shows the broadness of the system and the relevance of this approach to present different options for teams to overcome creativity blocks. By bringing techniques from different product development backgrounds, the KBS prototype presents knowledge for the teams to explore new mind-pathways and overcome difficulties by using adequate techniques. 


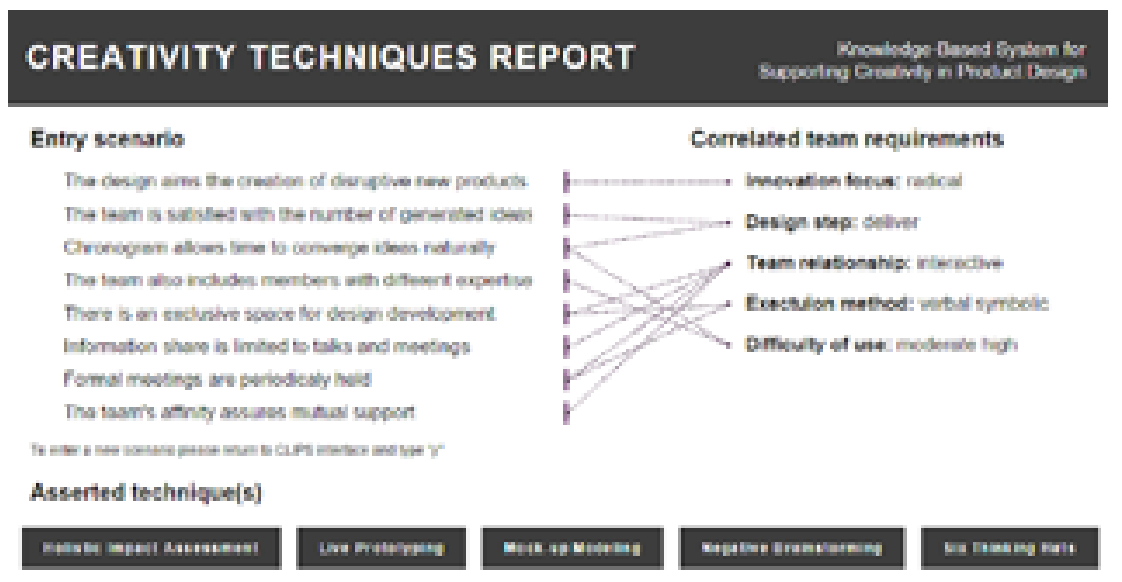

Figure 10: New heading interface of the creativity techniques report

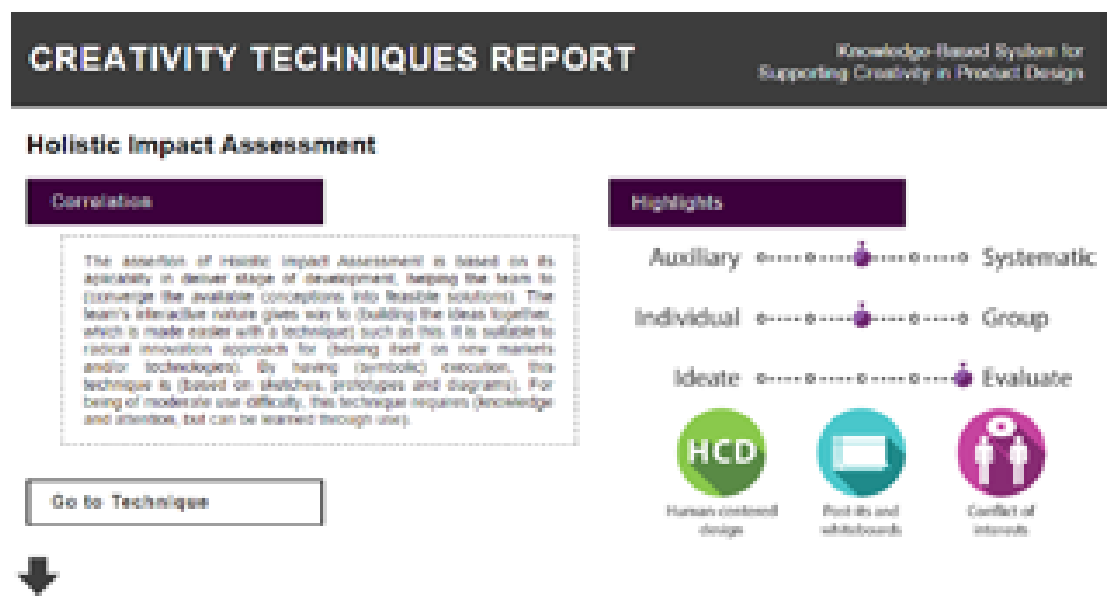

Figure 11: New interface of the creativity techniques report, presenting techniques correlation and highlights

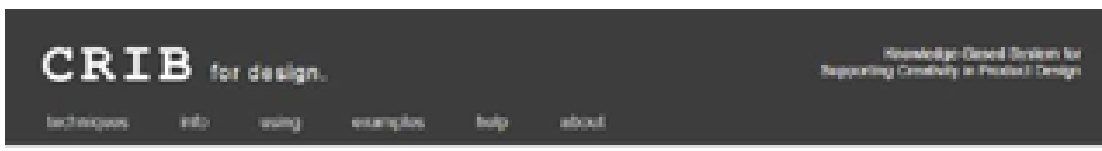

Hollstic Impact Assessment

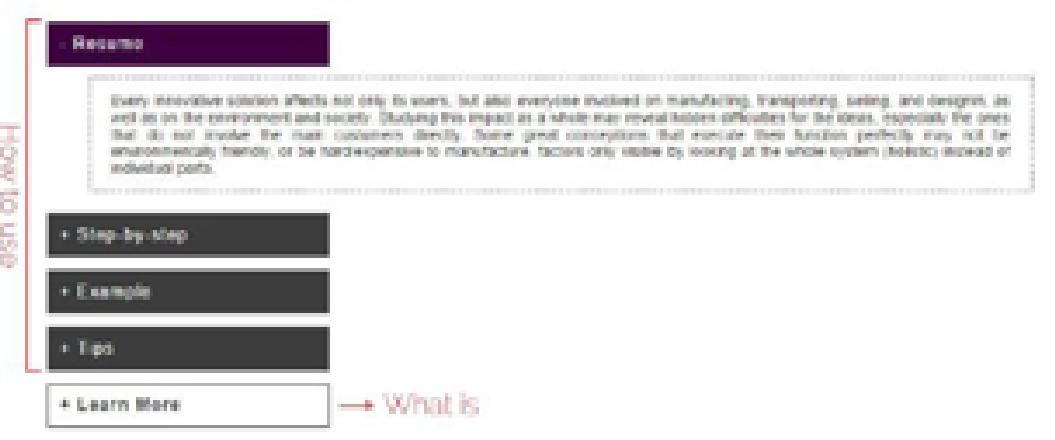

Figure 12: New webpage interface containing techniques explanation and further information

Answers from validation question 8 , presented on Figure 13, showed that 8 validators consider this KBS to be advantageous in group developments, and 3 to be also relevant in individual design. Up to 7 of the validators considered the system adequate for teams with limited knowledge about creativity techniques or no facilitator, to learn about other techniques, or when the team reaches creativity blocks and needs 
alternatives to continue the development. Respectively, 6 and 3 validators indicated that the system is useful in initial creation phases (to create basic conceptions) and posterior developments (when the team has multiple conceptions). Up to 5 of the validators considered the system useful in situations with time constraints to speed the creative process.

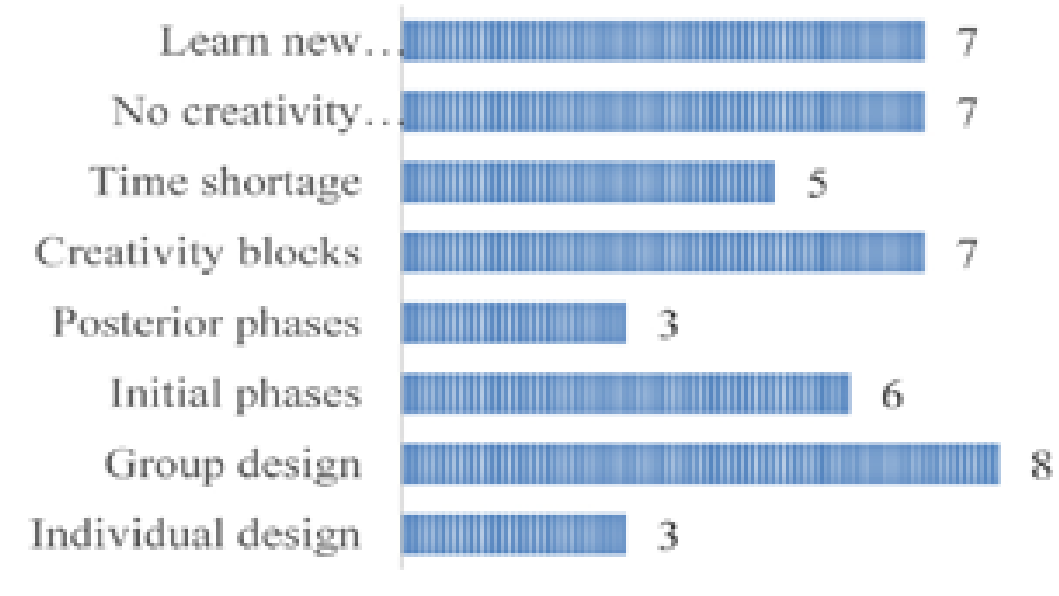

Figure 13: Bar chart representing answers from question 8: "In which situations do you consider the system useful?"

Other considerations brought by validators included:

- Translating the KBS into Portuguese for the first validation process to help comprehension, which was not considered an impeding factor and would be time consuming;

- To use a score system to grade techniques and then output the best, which will be accomplished in future implementations of the system. This construction would allow a better understanding of the design situation, but be more demanding on verification and validation. Nevertheless, the approach is seen as advantageous for better encompassing the singular nature of each design development;

- Small typing errors regarding words or constructions were indicated and corrected;

- As a measure of overall performance, validators gave an average of 4 on a scale from 1 to 5 , considering 5 as highest score.

\section{Conclusions}

To innovate is an essential skill for any organization aiming to maintain its market share in the current competitive world. One requisite for a company to be innovative is their members' ability to come up with different ideas that are useful and fulfill customers' needs. Even with upcoming deadlines, challenging users' needs, and conflicting stakeholder's requisites, it depends on the design team to create alternatives and build satisfactory solutions. By using design methodologies, the development process can be structured, giving creativity free-space to happen.

Human-centered design approaches are essential to allow focusing on the final 
user, since a market orientation and attention to users' needs increase the chances of a successful product or service (Baxter, 2011). The techniques made available by this approach are fundamental, but still unknown to many design teams, especially in engineering (Thompson and Lordan, 1999). The developed KBS aims to fulfill this bridge between design teams and creativity techniques, helping the development of more usable, viable and feasible products.

This usability study reveals the relevance of the prototype approach in this scenario. By selecting and presenting several techniques from different approaches, the system translates scattered information into a concise approach. The system was considered by validators as more adequate for group developments, especially for those with limited experience in creativity techniques or those lacking a facilitator. It was considered overall as a positive assistant and received good evaluations on this stage of development. The system potential is promising and many organizations, particularly those in search for innovative solutions, can benefit from this KBS approach.

\subsection{Future works}

Further developments will address the first diamond on the double diamond methodology. This is of great relevance to attain a more human-centered approach, including base techniques such as Persona, Canvas, Journey Mapping, among others. This cycle of implementation will focus on techniques to help building adequate design scenarios, assessing relevant problems and focusing the team on real needs.

Overall improvements on interface and interactivity are the main point at this stage of development, making this robust system more friendly, intuitive, and useful. The use of two different software interfaces (one in Java for initial questions and other in HTML for outputs) should be reevaluated, combining both preferably on a Web interface. Even though validators affirmed to be able to execute unknown techniques, the language and presentation form can only be confirmed in real scenarios accompanying design teams during their developments. The techniques were considered adequate, but the correlation and coherence of the KBS should still be further evaluated.

A refinement on initial questionnaire, interface, techniques description and explanations, and implementation of other techniques will gradually increase the system overall utility and usability. This step will be possible by further validation questionnaires with experts and non-experts, to provide information on how to improve the KBS's, as well as live testing of the prototype in real scenarios to evaluate influences of the system in design.

\section{Acknowledgements}

We would like to thank NEDIP-UFSC (Integrated Product Development Nucleus) for its facilities; and CNPq (National Council for Scientific and Technological Development) for its financial support. 


\section{REFERENCES}

AMABILE, T. Motivating Creativity in Organizations: On Doing What You Love and Loving What You Do. California Management Review, v. 40, n. 1, p. 39-58, 1997-10-01 1997.

AMABILE, T.; HADLEY, C. N.; KRAMER, S. J. Creativity under the gun. Harvard Business Review, v. 80, n. 8, p. 10, 2002.

BACK, N. et al. Projeto Integrado de Produtos: Planejamento, Concepção e Modelagem. São Paulo: Manole, 2008. 601 ISBN 852042208X, 9788520422083.

BAXTER, M. Projeto de Produto: Guia Pratico para o Design de Novos Produtos. 3rd. Edgard Blucher, 2011. 344 ISBN 9788521206149.

BELSKI, I.; ADUNKA, R.; MAYER, O. Educating a Creative Engineer: Learning from Engineering Professionals. Procedia CIRP, v. 39, p. 79-84, // 2016. ISSN 2212-8271.

BERTONCELLI, T.; MAYER, O.; LYNASS, M. Creativity, Learning Techniques and TRIZ. Procedia CIRP, v. 39, p. 191-196, // 2016. ISSN 2212-8271.

BOTEGA, L. F.; SILVA, J. C. Knowledge-Based System for Categorization and Selection of Creativity Support Techniques. International Journal of Knowledge Engineering and Management, v. 4, n. 10, p. 26, 2015. ISSN 2316-6517.

BOURGEOIS-BOUGRINE, S. et al. Engineering students' use of creativity and development tools in conceptual product design: What, when and how? Thinking Skills and Creativity, v. 24, p. 104-117, 6// 2017. ISSN 1871-1871.

BROWN, T. Design Thinking - uma metodologia poderosa para decretar o fim das velhas ideias. Rio de Janeiro: Campus, 2010. ISBN 9788535238624.

CHEN, Z.; JIA, X.; XIAO, Z. A Computational Cognitive Model of User Applying Creativity Technique in Creativity Support Systems. Procedia Computer Science, v. 55, p. 818-824, // 2015. ISSN 1877-0509.

COUNCIL, D. The Design Process: What is the Double Diamond? , 2015. Available at: < http://www.designcouncil.org.uk/news-opinion/design-process-what-double-diamond >. Acess: 29 Maio 2015.

FORTY, A.; SOARES, P. M. Objetos de desejo. Editora Cosac Naify, 2007. ISBN 8575035363.

GABRIEL, A. et al. Creativity support systems: A systematic mapping study. Thinking Skills and Creativity, v. 21, p. 109-122, 9// 2016. ISSN 1871-1871. 
GIARRATANO, J. C.; RILEY, G. Expert Systems: Principles and Programming. 4. Thomson Course Technology, 2005. ISBN 9780534384470.

IDEO. Human Centered Design: Toolkit. California: IDEO, 2011.

. The Field Guide to Human-Centered Design. California: IDEO, 2015. ISBN 9780991406319.

IKRAM, A.; QAMAR, U. Developing an expert system based on association rules and predicate logic for earthquake prediction. Knowledge-Based Systems, v. 75, p. 87103, 2// 2015. ISSN 0950-7051.

KWONG, C. K.; JIANG, H.; LUO, X. G. Al-based methodology of integrating affective design, engineering, and marketing for defining design specifications of new products. Engineering Applications of Artificial Intelligence, v. 47, p. 49-60, 1// 2016. ISSN 0952-1976.

MISNEVS, B.; DEMIRAY, U. The Role of Communication and Meta-communication in Software Engineering with Relation to Human Errors. Procedia Engineering, v. 178, p. 213-222, // 2017. ISSN 1877-7058.

MOSTERT, N. M. Diversity of the Mind as the Key to Successful Creativity at Unilever. Creativity and Innovation Management, v. 16, n. 1, p. 93-100, 2007. ISSN 1467-8691.

NIJSSEN, E. J.; LIESHOUT, K. F. M. Awareness, use and effectiveness of models and methods for new product development. European Journal of Marketing, v. 29, n. 10, p. 27-44, 1995.

PATEL, V. L.; KANNAMPALLIL, T. G. Cognitive informatics in biomedicine and healthcare. Journal of Biomedical Informatics, v. 53, p. 3-14, 2// 2015. ISSN 1532-0464.

RICH, E.; KNIGHT, K.; NAIR, S. B. Artificial Intelligence. India: Tata McGraw-Hill, 2009. ISBN 0070087709.

SANDERS, E. B.-N.; STAPPERS, P. J. Co-creation and the new landscapes of design. Co-design, v. 4, n. 1, p. 5-18, 2008. ISSN 1571-0882.

STARKEY, E.; TOH, C. A.; MILLER, S. R. Abandoning creativity: The evolution of creative ideas in engineering design course projects. Design Studies, v. 47, p. 47-72, 11// 2016. ISSN 0142-694X.

SANTANEN, E. L.; BRIGGS, R. O.; VREEDE, G.-J. D. A cognitive network model of creativity: a renewed focus on brainstorming methodology. Proceedings of the 20th international conference on Information Systems. Charlotte, North Carolina, USA: Association for Information Systems: 489-494 p. 1999. 
SILVA, J. C. Concurrent Engineering Perspective of Maintenance Aspects through an Expert System Prototype. AAAl's Spring Symposium Series, v. 4, p. 9, 1999.

SILVA, J. C.; MATELLI, J. A.; BAZZO, E. Development of a knowledge-based system for cogeneration plant design: Verification, validation and lessons learned. Knowledge-Based Systems, v. 67, p. 230-243, 9// 2014. ISSN 0950-7051.

STANTON, N. A.; BABER, C. Error by design: methods for predicting device usability. Design Studies, v. 23, n. 4, p. 363-384, 7// 2002. ISSN 0142-694X.

STARKEY, E.; TOH, C. A.; MILLER, S. R. Abandoning creativity: The evolution of creative ideas in engineering design course projects. Design Studies, v. 47, p. 47-72, 11// 2016. ISSN 0142-694X.

THOMPSON, G.; LORDAN, M. A review of creativity principles applied to engineering design. Proceedings of the Institution of Mechanical Engineers, Part E: Journal of Process Mechanical Engineering, v. 213, n. 1, p. 17-31, 1999. ISSN 0954-4089.

VAN KUIJK, J.; VAN DRIEL, L.; VAN EIJK, D. Usability in product development practice; an exploratory case study comparing four markets. Applied Ergonomics, v. 47, p. 308323, 3// 2015. ISSN 0003-6870.

VIANNA, M. et al. Design Thinking: Inovação em negócios. Rio de Janeiro: MJV Press, 2012. 85 ISBN 978-85-65424-00-4.

ŽNIDARŠIČ, J.; JEREB, E. Innovations and Lifelong Learning in Sustainable Organization. Organizacija, v. 44, p. 10, 2011. 